\title{
OS CONTRASTES DA MINERAÇÃO E A BUSCA DO DESENVOLVIMENTO SUSTENTÁVEL A PARTIR DA IMPLEMENTAÇÃO DE MEDIDAS MITIGADORAS, COMPENSATÓRIAS E DE PRÁTICAS VOLUNTÁRIAS
}

\author{
CONTRASTS OF MINING AND THE SEARCH FOR SUSTAINABLE \\ DEVELOPMENT BASED ON THE IMPLEMENTATION OF MITIGATING AND \\ COMPENSATING MEASURES AND VOLUNTARY PRACTICES
}

\author{
${ }^{1}$ Romeu Faria Thomé da Silva \\ ${ }^{2}$ Vinicius Diniz e Almeida Ramos
}

\section{RESUMO}

Este trabalho tem como intuito apontar os contrastes da mineração, atividade que, se por um lado propicia inúmeros benefícios econômicos e sociais ao País, também acarreta impactos negativos ao meio ambiente e às comunidades direta ou indiretamente afetadas. Avalia-se, a partir de pesquisa bibliográfica descritiva, o licenciamento ambiental como instrumento hábil a minimizar os efeitos indesejados da exploração mineral, com destaque para as medidas mitigadoras e compensatórias impostas aos empreendimentos que buscam a regularização socioambiental. Partindo de premissas antropocêntricas, e da irrefutável constatação de que o ser humano depende dos bens minerais para a satisfação de suas necessidades vitais, necessária se torna a utilização de instrumentos jurídicos que cumpram o papel de conciliar crescimento econômico e preservação do meio ambiente. Paralelamente, destaca-se a adoção voluntária, pelos empreendedores, de práticas ambientalmente corretas, que exercem um papel complementar, mas não menos relevante, em relação aos instrumentos de comando e controle previstos nas normas ambientais nacionais. Verifica-se, ao final, que as exigências legais, as determinações administrativas e a responsabilidade social corporativa por parte das empresas são mecanismos que, em seu conjunto, viabilizam a harmonização da atividade minerária com os preceitos do desenvolvimento sustentável.

Palavras-chave: Mineração, Desenvolvimento sustentável, Licenciamento ambiental, Medidas mitigadoras e compensatórias

\begin{abstract}
This paper has the purpose of pointing out the contrasts of mining, an activity that, on the one hand provides various economic and social benefits to the Country, but also brings negative impacts to the environment and to the directly or indirectly affected communities. Based on the descriptive bibliographic research, the environmental licensing is assessed as an effective instrument to minimize the unwanted effects of mineral exploration, highlighting the mitigating and compensatory measures imposed on enterprises that seek socio and environmental regulation. Starting from anthropocentric assumptions and the irrefutable evidence that the human being depends on the mineral assets to satisfy its vital need, it becomes necessary to use legal instruments that fulfill the role of reconciling economic growth and environmental preservation. In parallel, one highlights the voluntary adoption, by entrepreneurs, of correct environmental practices, which play a supplemental role, but not least, in relation to the command and control instruments provided for by national environmental standards. In the end, it is verified that legal requirements, administrative determinations, and corporate social responsibility by companies are mechanisms that, together, enable harmonization of mining activity with precepts of sustainable development.
\end{abstract}

Keywords: Mining, Sustainable development, Environmental licensing, Mitigating and compensating measures

\footnotetext{
1Doutor em Direito pela Pontificia Univesidade Católica -PUC, Belo Horizonte, Minas. Professor pela Escola Superior Dom Helder Câmara -ESDHC, Belo Horizonte, Minas Gerais, (Brasil) Email: tutortreinamento@gmail.com

2 Mestre em Direito pela Escola Superior Dom Helder Câmara -ESDHC, Belo Horizonte, Minas Gerais. Presidente da Comissão Permanente de Licitação do SESI e do SENAI de Minas Gerais, (Brasil).
} 


\section{INTRODUÇÃO}

Inequívoco que os produtos derivados da atividade minerária tornaram-se, na sociedade contemporânea, imprescindíveis para a manutenção da qualidade de vida. O grande dilema reside na constatação de que, apesar dos benefícios sociais e econômicos advindos da atividade minerária, efeitos negativos e indesejados são inerentes à exploração mineral.

A partir dessa dicotomia, o presente trabalho tem como objetivo analisar se as medidas mitigadoras e compensatórias previstas como condicionantes do licenciamento ambiental, juntamente com práticas voluntárias implementadas pelos empreendedores, são adequadas para conduzir a atividade minerária sob o postulado do desenvolvimento sustentável.

Adota-se a hipótese de que os mecanismos legais (como o licenciamento ambiental e suas respectivas condicionantes) à disposição do Poder Público, somados ao fomento estatal para a adoção de práticas ambientalmente adequadas por parte das mineradoras, se utilizados adequadamente, criam uma atmosfera favorável ao desenvolvimento dessa atividade econômica com respeito à proteção do meio ambiente.

A análise em tela tem como fundamentação teórica o princípio do desenvolvimento sustentável, caracterizado pela harmonização do crescimento econômico, da proteção ambiental e da equidade social, de tal modo que nenhum desses três fatores deve anular os demais. Assim, nem a proteção ambiental deve obstaculizar o crescimento econômico, nem este deve ser perseguido à custa da degradação ambiental.

A partir de ampla pesquisa bibliográfica descritiva serão destacados os aspectos positivos da mineração, especialmente relacionados a fatores econômicos e sociais, bem como aspectos negativos, apontando-se, sobretudo, os impactos sobre o meio ambiente para, em seguida, abordar-se o papel do licenciamento ambiental e das iniciativas dos empreendedores na conciliação da atividade minerária aos preceitos da sustentabilidade.

Inicialmente, serão apresentados os efeitos indesejados da mineração, presentes desde a implantação do empreendimento, passando pelo período de operação das minas e chegando até o encerramento da atividade, com o fechamento de mina. Destacar-se-á que esses efeitos não se restringem aos aspectos ambientais, mas alcançam também questões sociais relevantes.

Em seguida, serão destacados os benefícios advindos da mineração, como os relacionados ao crescimento econômico, sua importância para a balança comercial brasileira e a arrecadação de tributos em favor dos entes da Federação. A geração de trabalho e renda e os investimentos realizados pelos empreendedores minerários nas áreas de educação, saúde, 
infraestrutura, por sua vez, destacam-se dentre os aspectos sociais positivos decorrentes da atividade minerária.

Serão analisadas, ainda, as medidas mitigadoras e compensatórias a serem definidas pelos órgãos ambientais competentes no processo de licenciamento da atividade minerária, como instrumentos essenciais da política nacional de meio ambiente, sem perder de vista que o Poder Público pode, simultaneamente, estimular comportamentos voluntários dos empreendedores (como a adoção de códigos de conduta), em busca da efetiva implementação do desenvolvimento sustentável.

Ao final, procurar-se-á responder se os mecanismos de comando e controle (especialmente o processo administrativo de obtenção da licença ambiental pelos empreendedores), somados às práticas voluntárias adotadas pelas mineradoras, permitem que a mineração seja conduzida sob o manto da sustentabilidade.

\title{
2 IMPACTOS SOCIOAMBIENTAIS NEGATIVOS DA MINERAÇÃO
}

Praticamente todas as atividades humanas provocam, de uma forma ou de outra, impactos negativos no meio ambiente. Entretanto, algumas dessas atividades são essencialmente impactantes, como é o caso da mineração. Percebe-se que

\begin{abstract}
As atividades humanas, as chamadas econômicas, alteram o meio ambiente, sendo a mineração e a agricultura as duas atividades econômicas básicas da economia mundial. Através destas, o homem extrai recursos naturais que alimentam toda a economia. Sem elas, nenhuma das atividades subsequentes pode existir. A mineração e a agricultura, junto com a exploração florestal, a produção de energia, os transportes, as construções civis (urbanização, estradas, etc.) e as indústrias básicas (químicas e metalúrgicas) são os causadores de quase todo o impacto ambiental existente na terra. O impacto das demais atividades econômicas torna-se pouco significativo quando comparado às citadas anteriormente (SILVA, 2007, p. 30-31).
\end{abstract}

Os impactos adversos sobre o meio ambiente provocados pela atividade minerária estão relacionados, dentre outros, à movimentação de consideráveis volumes de terra, à supressão de vegetação, à destruição de habitats, ao afugentamento de espécies animais e à modificação da topografia. Esgotadas as capacidades produtivas das minas, sobram as cavas, as pilhas de estéreis, materiais desagregados das camadas superficiais e que não têm valor econômico, bem como as barragens de rejeitos (RIBEIRO e MENDES, 2013, p. 29).

Silva (2007, p. 34) salienta que na região carbonífera do Rio Grande do Sul e de Santa Catarina a poluição hídrica provocada pela drenagem ácida é o impacto mais 
significativo das atividades minerárias e de beneficiamento do carvão mineral. Por sua vez, no Quadrilátero Ferrífero, no Estado de Minas Gerais, a extração de ouro impõe a presença do elemento tóxico arsênio, que merece maior consideração no que tange aos efeitos da mineração no meio ambiente. Os reflexos da atividade minerária podem ser também vislumbrados diante de

Cenários devastados, população esquecida e economia mais dependente do que nunca. Estes foram os legados deixados por megaprojetos de mineração em cidades do interior de Minas Gerais como Ouro Preto, Itabira e Raposos. E, da forma como vem acontecendo a implantação do Projeto Minas Rio em Conceição do Mato Dentro, nova "menina dos olhos" da mineração no estado (sic) de Minas Gerais em pouco tempo a Serra da Ferrugem, em Conceição do Mato Dentro, dará lugar a um cenário semelhante ao das cidades anteriormente citadas (VIEIRA e XAVIER, 2013, p. 81).

A questão do fechamento de mina é outro ponto que provoca acirradas discussões, haja vista que a desativação de um empreendimento minerário - que, na maioria das vezes, ocorre pelo esgotamento das jazidas - acarreta inúmeras consequências indesejadas. Tais consequências não se vinculam única e exclusivamente aos aspectos ambientais, mas também implicam em questões econômicas e sociais. É nesse sentido que

\footnotetext{
Não só aspectos relacionados ao trabalho deverão estar previstos como também quaisquer outros impactos socioambientais decorrentes do encerramento das atividades, tais como: a redução das receitas das atividades econômicas total ou fortemente dependentes do projeto; a diminuição da arrecadação municipal, seja pela diminuição na arrecadação de tributos, seja pela suspensão da participação dos resultados da mineração; perda ou mudança da identidade local fortemente ligada à atividade extrativa mineral; dentre outros (RIBEIRO e MENDES, 2013, p. 41).
}

Há, ainda, certo consenso no sentido de que vivenciamos no Brasil um "desequilibrio entre os níveis nacional e local na partilha dos custos e dos benefícios gerados pela atividade mineradora", restando aos municípios a maior parte do ônus (reestruturação social, cultural, política e ecológica) e à União a maioria dos bônus, como divisas, tributos e desenvolvimento tecnológico (ENRIQUEZ, 2008, p. 123).

Vieira e Xavier (2013, p. 77) destacam que, em relação à geração de empregos, não raras vezes os municípios que recebem o empreendimento não dispõem de mão de obra quantitativa e qualitativamente suficiente, o que faz com que os postos de trabalho sejam ocupados por pessoas de outras cidades. Além disso, esses empregos são transitórios, não perdurando após o fim da atividade mineradora, estando, portanto, sujeito à natural volatilidade do setor minerário. 
Quanto ao comércio internacional de produtos minerais, colhem-se severas críticas pelo fato do País destinar à exportação basicamente produtos primários, denominados "commodities", com pouco valor agregado. As críticas fundamentam-se no fato de que

\footnotetext{
[...] sustentar um "desenvolvimento econômico" que é dependente dos preços das “commodities" é no mínimo questionável. Esse cenário configura uma situação de dependência, que por sua vez pode levar à subordinação.

[...] o Brasil, ao subsidiar cada vez mais a economia mineradora, seria dependente em relação ao capitalismo central, já que realiza trocas, por exemplo, de "commodities" ou produtos primários (no caso o minério), por produtos com alto valor agregado, o que somente aumenta sua condição de dependente e subdesenvolvido (VIEIRA e XA VIER, 2013, p. 78-79).
}

Inúmeras nações com vocação minerária são afetadas negativamente pela mineração. No Peru, por exemplo, o governo, a sociedade e as instituições nutrem significativa preocupação com o tema, especialmente no que tange aos conflitos em torno da implementação de operações de indústrias extrativistas e a exploração e uso de recursos não renováveis.

Segundo Tanaka e Huber (2007, p. 8), as diferenças de posição e de objetivos entre os diversos atores envolvidos - que constituem as situações de conflito - geram tensões permanentes que, não raro, desembocam em protestos e em enfrentamentos, exigindo atenção permanente das agências encarregadas em restabelecer a ordem pública e dos agentes externos que intervêm em favor de uma das partes.

As disputas por recursos naturais é o aspecto mais recorrente nos conflitos minerários peruanos. Porém, nem sempre esses conflitos têm como pano de fundo questões ecológicas no sentido estrito da palavra, vinculando-se precipuamente nos direitos de acesso à terra e à água, ou seja, os meios que constituem o fundamento da economia familiar.

A maior parte das mineradoras sabe que uma nova operação pode gerar protestos e que, para operar, além das autorizações legais, é preciso contar com uma espécie de "licença social". Por isso, ensinam Tanaka e Huber (2007, p. 10), parte das ações de responsabilidade social e de relações públicas das empresas está orientada para a diminuição das tensões existentes e para a redução do estímulo aos protestos.

Por sua vez, a indústria de mineração da Índia - ressaltam Daisy e Das (2013, p. 76) - está sob crescente pressão em suas regiões tradicionais, em que o esgotamento do corpo de minério e as restrições de acesso à terra são óbices às operações. $\mathrm{Na}$ opinião dos autores, a solução para esse problema está na promoção, pelas companhias mineradoras, de uma imagem menos negativa junto às comunidades instaladas nas regiões tradicionais. 
As atividades de mineração, em regra, envolvem alto grau de impactos ambientais, que se estendem muito além das áreas mineradas. Esses impactos começam com a exploração da atividade, permanecem durante a extração e processamento e continuam após o fechamento das minas. Lembram Daisy e Das (2013, p. 73) que anos de mineração não regulamentada na Índia não vieram sem alta dos custos ambientais: os impactos sociais e ecológicos associados à atividade minerária são significativos e seu gerenciamento é nitidamente complexo. A descoberta, extração e processamento de recursos minerais é considerado como uma das mais destrutivas atividades econômicas.

Acidentes no processo de extração apresentam-se como uma das mazelas sociais da mineração de carvão na Turquia. Segundo a imprensa internacional, explosões em minas de carvão são corriqueiras naquele país, sobretudo nas minas exploradas pela iniciativa privada, que não observam as regras de segurança exigidas para a atividade. (UNIVERSO ONLINE, 2014).

A explosão em uma mina de carvão no distrito de Soma, ocorrido em maio de 2014, matou 301 (trezentos e um) mineiros e deixou inúmeros feridos. "A tragédia expõe de maneira visceral e cruel as condições degradantes a que ainda são submetidos inúmeros trabalhadores da atividade minerária" (ARAÚJO e THOMÉ, 2015, p. 115). Outra explosão havia ceifado a vida de 236 (duzentos e trinta e seis) mineiros na mina de Zonguldak em 1992, também na Turquia.

Observa-se, portanto, que os conflitos acerca da mineração não se restringem à realidade brasileira. Pelos impactos provocados pela atividade e considerando que o postulado do desenvolvimento sustentável, na atualidade, impõe-se a praticamente todas as nações do mundo, o enfrentamento das questões ambientais, econômicas e sociais torna-se transfronteiriço.

\section{IMPACTOS ECONÔMICOS E SOCIAIS POSITIVOS DA MINERAÇÃO}

Não obstante os indiscutíveis impactos socioambientais negativos decorrentes da atividade minerária, é preciso contrabalançá-los com os seus aspectos positivos. Importante lembrar que a mineração é base da economia nacional e que a utilização dos recursos minerais possibilita a manutenção e a melhoria da qualidade de vida humana. Nesse sentido,

Como conceber a existência sem a água? E sem a energia elétrica, cujo fornecimento depende do cobre e do alumínio? E os fertilizantes, combustíveis, areia e argila, cimento e cal? E o silício? Pode-se hoje viver sem automóvel, aeronaves 
computadores? Impossível imaginar vida e progresso sem os minerais, os metais e seus compostos. Fontes de energia da terra, presentes em tudo, o mundo depende deles desde quando o homem, alguns séculos antes de Cristo, amassou o cobre pela primeira vez para fazer uma ferramenta. A mineração é a base de tudo. Essencial e indispensável(LÉO CHRISTIANO EDITORIAL, 2006, p. 31).

A vocação mineral brasileira tornou-se evidente a partir do final do século XVII, quando grandes quantidades de ouro foram extraídas dos córregos e ribeirões de Minas Gerais. Foi, entretanto, no século XVIII, que a mineração se expandiu e passou a dominar a cena econômica, propiciando ao Brasil migrar da economia açucareira para a mineradora. Pode-se afirmar, nesse contexto, que a atividade minerária impulsionou significativamente a economia nacional.

A produção mineral ainda exerce papel fundamental no desenvolvimento nacional contemporâneo. A pujança da mineração brasileira decorre da existência de reservas de uma diversificada gama de produtos (metálicos e não metálicos), que colocam o Brasil entre os seis mais importantes países minerais do mundo. É induvidoso que as terras brasileiras foram privilegiadas pela natureza, pois além de sua inigualável biodiversidade, seu subsolo é rico em minérios capazes de propiciar o seu desenvolvimento econômico e social. Segundo o IBRAM (2012, p. 8), o País ocupa o primeiro lugar nas reservas de nióbio e tantalita; o segundo lugar em caulim; o terceiro em estanho; o quinto em bauxita e minério de ferro e o sexto lugar nas reservas de zinco e manganês.

No ano de 2013, a produção mineral brasileira respondeu por $13,89 \%$ do minério de ferro mundial, por $13,2 \%$ da produção de bauxita, por $5,98 \%$ de níquel, por $2,8 \%$ do alumínio e por $2,7 \%$ do ouro (IBRAM, 2014a, p. 30).

Conforme levantamento do IBRAM (2013), Minas Gerais é o principal Estado minerador do País, extraindo mais de 160 milhões de toneladas por ano de minério de ferro. Mais de 250 municípios mineiros têm dentre suas atividades a mineração. Dos dez maiores municípios mineradores brasileiros, sete estão em Minas Gerais (Itabira é o maior deles). Mais de 300 minas estão em operação.

Os produtos minerários representam, reconhecidamente, importante fonte de divisas geradas através das exportações, podendo-se afirmar que a mineração, ao lado da agricultura, é um dos pilares da sustentação econômica do País.

Em 2012, as exportações brasileiras atingiram a cifra de US\$ 242 bilhões. Desse total, US\$ 38,6 bilhões (cerca de 16\%) originaram-se de bens minerais primários. Em 2013 o volume de exportações gerais praticamente não se alterou, mas a parcela reservada aos produtos da mineração subiu para US\$ 40,5 bilhões, ou seja, 16,7\%. De todos os bens 
minerários, o minério de ferro ocupa posição de destaque (em 2013 o montante exportado chegou a pouco mais de US\$ 32 bilhões), sendo seguido pelo ouro, nióbio, cobre, e outros minerais (IBRAM, 2014a, p. 31).

Somente o Estado do Pará foi responsável por US\$13,1 bilhões das exportações de produtos minerários no ano de 2012; valor que no ano seguinte elevou-se para US\$ 13,9 bilhões, tendo sofrido uma redução em 2014, fixando-se em US\$ 12,1 bilhões (SIMINERAL, 2015, p. 168).

Segundo dados do MDIC (2015), a balança comercial brasileira de 2013 encerrou o ano apresentando um saldo positivo de US\$ 2,56 bilhões. Conclui-se, portanto, que a produção e a exportação mineral foi, em grande parte, responsável pelo superavit comercial brasileiro naquele ano, o que denota a importância dessa atividade para a economia nacional.

Outro ponto relevante da atividade minerária diz respeito à geração de empregos, diretos e indiretos. Destaca o IBRAM (2014a, p. 29) que a cada posto de trabalho com carteira assinada, uma mineradora estimula outros treze postos em fornecedores, em subcontratados e na indústria de transformação de base mineral. No ano de 2013, a atividade minerária foi responsável por cerca de dois milhões de empregos (diretos e indiretos) no Brasil.

Segundo o SIMINERAL (2015, p. 200), no ano de 2014 as empresas mineradoras responderam pela geração de 20.133 empregos diretos no Estado do Pará; número que sobe para 281.862 postos de trabalho se forem considerados os empregos reflexivos.

Informação também relevante é que a mineração, como atividade que movimenta bilhões de dólares anualmente, é importante fonte de recursos tributários para o Estado. Além dos tributos propriamente ditos, a atividade minerária impõe aos mineradores a obrigação de pagamento a Estados, Distrito Federal e Municípios da denominada Compensação Financeira pela Exploração de Recursos Minerais (CFEM), instituída pela Lei 7.990/1989, cujo objetivo é compensar os entes federados em face dos impactos sociais e econômicos que a mineração provoca no meio ambiente, na comunidade e na economia local e regional (THOMÉ, 2014, p. 495).

Apenas para se ter uma ideia da dimensão dos recursos advindos da CFEM, no ano de 2013 o total arrecadado com essa Contribuição no Brasil foi de R\$2,37 bilhões, sendo que só o Estado de Minas Gerais arrecadou R\$ 1,2 bilhão (IBRAM, 2013), enquanto o Estado do Pará foi responsável pela arrecadação de R 804 milhões (SIMINERAL, 2015, p. 201).

Importante destacar a ponderação de Enríquez (2008, p. 114), para quem "mais do que a determinação do montante da renda mineral, é o uso que se faz dessas rendas o ponto mais nevrálgico sobre as possibilidades de desenvolvimento de uma região de base mineira.' 
Em outros termos, cabe aos Poderes Públicos utilizarem as rendas provenientes da mineração (dentre elas os tributos e a CFEM) para alavancar e dar sustentação (econômica e ambiental) ao desenvolvimento das localidades.

Quanto ao desenvolvimento social, vale lembrar que o Índice de Desenvolvimento Humano - IDH vem sendo utilizado desde 1993 pelo Programa das Nações Unidas para o Desenvolvimento - PNUD, como forma de classificar os países levando em conta seu grau de desenvolvimento humano.

Como atividade econômica das mais relevantes, a mineração afeta positivamente os índices utilizados na apuração do IDH. É preciso reconhecer que

\begin{abstract}
A mineração reflete positivamente na qualidade de vida dos cidadãos. É pouco percebido pela população, por exemplo, que o Índice de Desenvolvimento Humano - IDH dos municípios onde ocorre a mineração é maior do que a média do IDH dos Estados onde se localizam e superior, também, ao dos municípios onde não há essa atividade econômica. [...]

Promover a ascensão socioeconômica da população é o cerne de qualquer política adotada pela administração pública, e a mineração é um dos itens fundamentais a ser levado em conta no planejamento e na execução dos projetos voltados para o progresso do país (IBRAM, 2014a, p. 8).
\end{abstract}

Apenas a título exemplificativo, cabe recordar que, de acordo com o PNUD (2013), o IDH do Estado de Minas Gerais, em 2010, foi de 0,731, sendo que a cidade de Nova Lima importante município minerador -, classificada em $17^{\circ}$ lugar dentre os municípios brasileiros, apresentou IDH de 0,813.

Grande parte das mineradoras cumpre importante papel social nas comunidades onde se instalam. O Instituto Alcoa, por exemplo, investiu em 2013 mais de R\$ 4,0 milhões no Programa de Apoio a Projetos Locais, no município de Juruti, no Estado do Pará. Esses recursos foram aplicados nas áreas de educação, saúde, meio ambiente, trabalho e renda, segurança e governança (SIMINERAL, 2015, p. 121-122). Além disso,

\footnotetext{
Sobre as iniciativas sociais da Vale, maior mineradora do País e com diversas ações no Pará, os destaques de 2014 foram diversos. Houve a conclusão das obras do campus Parauapebas do Instituto Federal de Educação, Ciência e Tecnologia do Pará (IFPA), com investimentos que somaram mais de R\$ 46 milhões. Compreendem doação do terreno, construção de toda a infraestrutura do prédio, compra de mobiliário e implantação de laboratórios e equipamentos. Desde a fase de implantação do projeto Sossego, a Vale vem realizando investimentos no município de Canaã dos Carajás (PA), que envolvem toda a infraestrutura da cidade, contribuindo para a melhoria dos serviços nas áreas de saúde, educação, esporte, cultura, segurança pública, saneamento básico e infraestrutura de transporte. Estas ações se somam à atuação da Fundação Vale e à implantação do projeto S11D (SIMINERAL, 2015, p. 122-123).
} 
São inquestionáveis, sob uma perspectiva antropocêntrica, tanto os impactos positivos quanto os negativos decorrentes da atividade minerária. Desta forma, necessário criar e aprimorar instrumentos jurídicos capazes de ampliar significativamente os positivos e, simultaneamente, eliminar ou reduzir os negativos, densificando, assim, o princípio do desenvolvimento sustentável em relação à mineração nacional.

As normas regulamentadoras da atividade de mineração, até bem pouco tempo analisadas exclusivamente sob o enfoque econômico passam, sobretudo a partir da consagração do meio ambiente equilibrado como direito fundamental constitucionalmente garantido, a ser interpretadas sob a luz do princípio do desenvolvimento sustentável e das normas de proteção ambiental. Assim, a análise dos institutos que regem a atividade econômica da mineração deve ser realizada a partir das garantias socioambientais conquistadas ao longo dos últimos anos.

$\mathrm{O}$ ordenamento jurídico pátrio apresenta uma série de instrumentos capazes de exercer a função de elo entre atividade minerária e proteção ambiental, como as avaliações de impacto ambiental, as audiências públicas ambientais, o zoneamento ambiental, a criação de espaços territoriais especialmente protegidos e os instrumentos econômicos, todos previstos na Lei 6.938/1981, que dispõe sobre a política nacional do meio ambiente.

Dentre eles destaca-se, no presente trabalho, o licenciamento ambiental e, mais especificamente, as medidas mitigadoras e compensatórias, como relevantes instrumentos jurídicos capazes de materializar o princípio do desenvolvimento sustentável na mineração nacional.

\section{AS CONDICIONANTES DO LICENCIAMENTO AMBIENTAL E AS PRÁTICAS VOLUNTÁRIAS COMO INSTRUMENTOS DE IMPLEMENTAÇÃO DO DESENVOLVIMENTO SUSTENTÁVEL NA MINERAÇÃO}

Nas últimas décadas, o mundo experimentou profundas mudanças na questão da competitividade. Os aspectos éticos e de sustentabilidade vêm ganhando cada vez mais relevância. Os objetivos tradicionais de maximização de vendas (gerando valor para os consumidores) e de rentabilidade (gerando valor para os acionistas) somam-se agora aos objetivos de responsabilidade socioambiental. Esse processo decorre da necessária conjugação entre resultados econômicos, sociais e ambientais, que constituem a base da responsabilidade social corporativa (SÁNCHEZ e SANTOS, 2010, p. 16). 
Daisy e Das (2013, p. 74) salientam que a mineração é atualmente a quinta maior atividade industrial do mundo, desempenhando um papel crucial no desenvolvimento da economia mundial. Os negócios envolvendo as commodities minerais representam substancial parcela de todo o comércio internacional. Desse modo, muitas agências internacionais desenvolveram orientações ambientais para as operações de mineração, enquanto grandes empresas do segmento têm adotado códigos de conduta com vistas a minimizar os efeitos nocivos da atividade para as comunidades envolvidas.

Em artigo que trata da mineração na Cataluña, Sánchez e Santos (2010, p. 20) abordam a importância da responsabilidade social corporativa, destacando que merece uma menção especial o compromisso das empresas mineradoras com seu entorno e a preocupação com os stakeholders internos (os trabalhadores), eis que mais de $50 \%$ das indústrias da mineração na Espanha aplicam efetivamente procedimentos de tratamento dos resíduos na origem e códigos de conduta. Os resultados mostram que, em geral, as porcentagens de práticas de responsabilidade social corporativa relacionadas com o meio ambiente (trabalhos de recuperação das áreas exploradas, procedimentos de redução de resíduos na origem e controle de consumo das fontes de energia) superam as práticas relacionadas com ações sociais e com o fomento das comunidades locais.

De toda forma, não se vislumbra a possibilidade de atribuir aos códigos de conduta e à responsabilidade social corporativa (ambos de adoção voluntária) o título de principais mecanismos de harmonização entre exploração dos recursos naturais e proteção das garantias socioambientais. Necessária a conjugação de elementos concorrenciais com a implementação de instrumentos de comando e controle definidos pelo Poder Público.

Para tanto, os ordenamentos jurídicos de diversos países apresentam instrumentos e traçam os limites de atuação dos empreendimentos de significativo impacto ambiental. Dessa forma, torna-se possível a autorização, pelo Poder Público, da exploração de recursos minerais, não obstante seus efeitos socioambientais negativos.

No Brasil, a regularização socioambiental das atividades de significativo impacto passa necessariamente pelo licenciamento ambiental, procedimento administrativo instaurado no âmbito da Administração Pública competente para avaliar e monitorar os impactos decorrentes da atividade, a partir de parâmetros definidos pela Lei Complementar 140, de 08/12/2011, que estabelece critérios de definição de competências para a atuação dos órgãos ambientais federais, estaduais e municipais. 
Nos termos do inciso I do artigo $8^{\circ}$ da Resolução CONAMA 237/1997, que dispõe sobre a revisão e complementação dos procedimentos e critérios utilizados para o licenciamento ambiental, o Poder Público concederá a Licença Prévia (LP) quando da aprovação da localização e concepção do projeto, na fase preliminar do planejamento do empreendimento, atestando a viabilidade ambiental e estabelecendo os requisitos básicos e condicionantes a serem atendidos nas próximas fases de sua implementação.

Observadas as determinações do órgão ambiental, será concedida a Licença de Instalação (LI), autorizando a instalação do empreendimento ou atividade de acordo com as especificações constantes dos planos, programas e projetos aprovados, incluindo as medidas de controle ambiental e demais condicionantes, de acordo com o inciso II do artigo $8^{\circ}$ da Resolução CONAMA 237/97.

Por fim, será concedida a Licença de Operação (LO), que autoriza a operação da atividade ou empreendimento, após a verificação do efetivo cumprimento das condicionantes apostas às licenças anteriores, incluindo-se as medidas de controle ambiental e condicionantes determinadas para a operação (artigo $8^{\circ}$, inciso III da Resolução CONAMA 237/97).

Destacam-se, no procedimento trifásico de licenciamento ambiental, as condicionantes ambientais, que geralmente se materializam em determinações de implementação de medidas mitigadoras e/ou compensatórias a serem cumpridas pelo empreendimento. Caracterizam-se como medidas de controle ambiental, de caráter técnico, identificadas a partir de avaliações de impacto ambiental da atividade e fixadas na licença ambiental com o objetivo de disciplinar o exercício de determinada atividade impactante.

Assim, para os casos em que não seja possível evitar a intervenção da atividade sobre o meio ambiente (como nas atividades minerárias que, por suas características intrínsecas, provocarão efeitos socioambientais negativos, mas que são indiscutivelmente necessárias para o desenvolvimento social e econômico), o órgão ambiental licenciador deve definir as condicionantes necessárias para evitar ou atenuar (mitigar) seus impactos negativos sobre o meio ambiente. Pode exigir que o empreendimento adote medidas de controle de emissões de particulados, como aspersão de água em áreas onde se verifique o desnudamento, movimentação de solo ou circulação de veículos em vias não pavimentadas, dentre outras condicionantes.

Todavia, em certos casos, não é possível sequer a mitigação dos impactos ambientais. Deverá então o órgão licenciador definir encargos compensatórios ao empreendedor, calcados no princípio do usuário-pagador. Quando é necessária, por exemplo, a intervenção em áreas ambientalmente protegidas, como as de vegetação de Mata Atlântica, 
o órgão ambiental deverá condicionar a exploração mineral à destinação, pelo empreendedor, de área equivalente à extensão da área desmatada, com as mesmas características ecológicas, na mesma bacia hidrográfica, sempre que possível na mesma microbacia, como forma de compensar os impactos decorrentes da atividade minerária.

Não obstante a imposição de medidas mitigadoras e compensatórias pelos órgãos ambientais competentes, o IBRAM (2014a, p. 33) salienta que várias empresas de mineração no Brasil vêm adotando estratégias direcionadas à gestão da biodiversidade como compromisso na manutenção de sua licença de operação. Os compromissos assumidos pelos empreendedores minerários buscam ir além das medidas ambientais impostas pelas leis, incorporando a responsabilidade socioambiental como estratégia para o adequado desempenho de suas atividades.

Inúmeras medidas têm sido tomadas pelas empresas do setor para evitar (prevenir), minimizar e/ou compensar tais impactos nas áreas apropriadas para a atividade mineral. Atualmente, o compromisso com a conservação da biodiversidade é ingrediente essencial do desenvolvimento sustentável das indústrias desse segmento.

Conforme levantamento do IBRAM (2014a, p. 34), as mineradoras de minério de ferro, somente em 2013, foram responsáveis pela proteção de 1,1 milhão de hectares, pela revegetação de 7 mil hectares e pela produção de 5 milhões de mudas de árvores. Números também significativos se apresentam na mineração de bauxita, ouro, fosfato e níquel.

No que se refere, por exemplo, à água - bem dos mais preciosos e imprescindíveis para a atividade minerária - é interessante notar que sua utilização não se limita ao processo de lavra, mas se estende para as atividades de beneficiamento, transporte dos minérios e encerramento de mina. Para a mineração, portanto, a água é fator estratégico, escasso e de alto valor econômico. É por isso que

\footnotetext{
O contexto hidrológico no qual se localizam os veios é importante para determinar a eficiência e a viabilidade técnica e econômica de uma lavra. As empresas de mineração planejam a gestão de recursos hídricos em todas as fases da mineração, desde a pesquisa até o pós-fechamento, com ferramentas apropriadas, desenhando e implantando as medidas preventivas e corretivas mais adequadas (IBRAM, 2014a, p. 35).
}

Em razão da necessidade de utilização de grandes volumes de água, a implementação de processos de reciclagem e recirculação tornou-se usual no setor mineral brasileiro. As fontes mais comuns provêm dos reservatórios de barragem de rejeitos ou resultam dos processos de desaguamento por filtragem e espessamento. 
De acordo com o IBRAM (2014a, p. 37), os índices de reciclagem ou recirculação observados em 2013 são exitosos. Na extração do minério de ferro, o resultado ficou entre $65 \%$ e $90 \%$ de água reutilizada, ao passo que nas minas de ouro esse índice foi de $55 \%$ a $81 \%$ e nas minas de carvão de $95 \%$ a $100 \%$.

As barragens de rejeitos são também um ponto crítico no que concerne aos impactos ambientais provenientes da atividade minerária. Nesse tema, os maiores avanços observados decorreram da evolução e consolidação do arcabouço legal crescente após o ano de 2000, em especial no que tange à segurança de barragens, ao desenvolvimento de uma nova abordagem para os projetos e, também, ao avanço tecnológico dos processos de beneficiamento de minério. É evidente que

\begin{abstract}
O aumento dos dispositivos legais estabelecidos a partir de 2000 implicou mudança das práticas de gestão de barragens e de depósitos de estéril, até então adotadas pelas empresas de mineração, coma necessidade de atendimento aos requisitos e exigências sobre os critérios de elaboração dos projetos, de operação da recuperação e fechamento destas estruturas, além de permitir aos órgãos fiscalizadores mecanismos de controle, licenciamentos e autuações (IBRAM, 2014b, p. 65).
\end{abstract}

Cabe observar que a proteção da biodiversidade, a reutilização de recursos hídricos e o reflorestamento de áreas impactadas pelas mineradoras decorrem, muitas vezes, de exigência legal e/ou do órgão ambiental competente para o licenciamento ambiental da atividade, e não apenas de sua responsabilidade socioambiental. De toda forma, trata-se de iniciativa louvável de alguns empreendimentos adotar medidas mitigadoras e compensatórias como complementares àquelas já normalmente definidas pelos órgãos ambientais licenciadores.

As medidas mitigadoras e compensatórias, sobretudo as exigidas pelo órgão ambiental no procedimento de licenciamento ambiental, juntamente com as ações voluntárias adotadas pelos empreendedores minerários, funcionam, portanto, como instrumentos juridicamente válidos, capazes de conciliar o desenvolvimento de uma atividade econômica (mesmo que potencialmente impactante) com a garantia do equilibrio ambiental, ambos previstos na Constituição da República de 1988.

\title{
5 CONCLUSÃO
}

Há que se reconhecer a imprescindibilidade da atividade minerária. Primeiramente, porque o estilo de vida da sociedade contemporânea implica no consumo de bens e serviços que, 
inevitavelmente, para sua produção e oferta, dependem da utilização de matérias primas minerais. Além disso, essa atividade promove o desenvolvimento econômico e social do País, na medida em que é fonte de recursos para os entes públicos (por meio do recolhimento de impostos e do pagamento da CFEM), é importante elemento de equilibrio na balança comercial, é geradora de emprego e renda e, por fim, é responsável por investimentos privados na área social, como educação, saúde, lazer e infraestrutura nas localidades onde se instala.

Por outro lado, não há como ignorar o fato de que a mineração provoca significativos impactos ambientais. A supressão de vegetação e suas consequências (comprometimento de habitats e afugentamento de espécies animais), a modificação da topografia e as indesejadas consequências socioeconômicas do fechamento de mina, são resultados que se contrapõem aos benefícios da atividade minerária.

O desafio, portanto, é harmonizar a mineração aos contornos da proteção e preservação ambiental, de modo que se possa alcançar o desenvolvimento sustentável, postulado previsto na Constituição da República.

Para tal desiderato, o processo de licenciamento ambiental - incluindo em seu bojo a imposição de medidas mitigadoras e compensatórias - é instrumento da mais alta relevância, que deve ser adotado pelo Poder Público com respaldo nos princípios da legalidade, impessoalidade, proporcionalidade e razoabilidade. Paralelamente, devem ser incentivadas pelo Estado a adoção voluntária, pelos empreendedores minerários, de códigos de conduta e práticas de responsabilidade social corporativa.

Esse conjunto de medidas - parte delas definidas pelas normas e pelo Poder Público, parte adotada voluntariamente pelas mineradoras - permite o desenvolvimento da atividade econômica minerária (imprescindível para a sociedade contemporânea), ao mesmo tempo em que proporciona o surgimento de atmosfera favorável para a proteção e preservação dos recursos naturais. Esse processo harmônico e integrado representa, a rigor, a adoção do primado do desenvolvimento nacional sustentável, que deve, necessariamente, ser observado na condução das atividades econômicas brasileiras.

\section{REFERÊNCIAS}

ARAUJO, Carlos Eduardo; THOMÉ, Romeu. Germinal turco: as mazelas socioambientais nas minas de carvão em pleno século XXI. Revista de Direito Ambiental, vol. 78. São Paulo: Revista dos Tribunais, 2015. 
BRASIL. Lei Complementar n. 140, de 8 de dezembro de 2011. Fixa normas, nos termos dos incisos III, VI e VII do caput e do parágrafo único do art. 23 da Constituição Federal, para a cooperação entre a União, os Estados, o Distrito Federal e os Municípios nas ações administrativas decorrentes do exercício da competência comum relativas à proteção das paisagens naturais notáveis, à proteção do meio ambiente, ao combate à poluição em qualquer de suas formas e à preservação das florestas, da fauna e da flora; e altera a Lei n⿳⺈ 6.938, de 31 de agosto de 1981. Disponível em: <http://www.planalto.gov.br/ccivil_03/leis/LCP/Lcp140.htm>. Acesso em: 9 ago. 2015.

BRASIL. Conselho Nacional do Meio Ambiente - CONAMA. Resolução CONAMA n. 237, de 19 de dezembro de 1997. Disponível em: <http://www.mma.gov.br/port/conama/res/res97/res23797.html〉. Acesso em: 9 ago. 2015.

CANOTILHO, José Joaquim Gomes; LEITE, José Rubens Morato. Direito constitucional ambiental brasileiro. 5. ed. rev. São Paulo: Saraiva, 2012.

DAIZY, Daisy; DAS, Niladri. Sustainable develoment for Indian mining sector. OIDA International Journal of Sustainable Development. Dhanbad: OIDA, v. 6, n. 7, p. 71-82, 2013. Disponível em: <http:/ssrn.com/abstract=2383433〉. Acesso em: 15 mar. 2014.

ENRIQUEZ, Maria Amélia. Mineração: maldição ou dádiva? São Paulo: Signus, 2008.

UNIVERSO ONLINE - UOL. Explosão em mina de carvão na Turquia deixa mais de 200 mortos. São Paulo: UOL, 14 maio 2014. Disponível em: <http//zip.net/bknVRw> Acesso em: 11 jun. 2014.

INSTITUTO BRASILEIRO DE MINERAÇÃO - IBRAM. A indústria da mineração: para o desenvolvimento do Brasil e a promoção da qualidade de vida do brasileiro. Brasilia: IBRAM, 2014a.

INSTITUTO BRASILEIRO DE MINERAÇÃO - IBRAM. Gestão para a sustentabilidade na mineração: 20 anos de história. Brasilia: IBRAM, 2014 b.

INSTITUTO BRASILEIRO DE MINERAÇÃO - IBRAM. Informações e análises da economia mineral brasileira. 7. Ed. Brasilia: IBRAM, dez./2012.

INSTITUTO BRASILEIRO DE MINERAÇÃO - IBRAM. Informações sobre a economia mineral do Estado de Minas Gerais. Brasilia: IBRAM, 2013.

LÉO CHRISTIANO EDITORIAL. Augusto Trajano de Azevedo Antunes: o homem que realizava. Rio de Janeiro: Léo Christiano Editorial, 2006.

MACHADO, Paulo Affonso Leme. Direito ambiental brasileiro. 22. ed., rev., ampl. e atual. São Paulo: Malheiros, 2014.

MINISTÉRIO DE DESENVOLVIMENTO INDÚSTRIA E COMÉRCIO - MDIC. Balança comercial brasileira 2013. Disponível em: <http://www.mdic.gov.br/arquivos/dwnl_1388692200.pdf >. Acesso em: 15 mar. 2015.

PROGRAMA DAS NAÇÕES UNIDAS PARA O DESENVOLVIMENTO - PNUD. Ranking IDHM $\quad$ Municípios 2010. Disponível em: 
<http://www.pnud.org.br/atlas/ranking/Ranking-IDHM-Municipios-2010.aspx>. Acesso em: 13 jul.2015.

RIBEIRO, José Cláudio Junqueira; MENDES, Samuel Felisbino. A participação no fechamento de mina no direito comparado. Veredas do Direito. Belo Horizonte: Escola Superior Dom Helder Câmara, v. 10, n. 20, p. 23-54, jul./dez. 2013.

SÁNCHEZ, Carla Vintró; SANTOS, Jordi Fortuny. Estudio empírico de las prácticas de responsabilidad social corporativa en la minería de áridos en Cataluña. Dirección y Organización. Cataluña: Universidad Politécnica de Catalunya, n. 42, p. 16-23, dic. 2010. Disponível em: <http://revistadyo.es/index.php/dyo/article/view/344/358>. Acesso em: 16 mar. 2014.

SILVA, João Paulo Souza. Impactos ambientais causados por mineração. Revista Espaço da Sophia. Tomazina: Espaço da Sophia, n. 8, p. 29-47, nov. 2007.

\section{SINDICATO DAS INDÚSTRIAS MINERAIS DO ESTADO DO PARÁ - SIMINERAL.} Anuário mineral do Pará. 4. ed. Belém: SIMINERAL, 2015.

TANAKA, Martín; HUBER, Ludwig et al. Minería y conflic to social. Economía y Sociedad. Lima: CIES, n. 65, p. 7-17, oct. 2007. Disponível em: <http://www.ciefa.org/acrobat/modulos/LECTURA\%20\%20CUATRO $\% 20 \% 20$ MODULO $\%$ 20OCHO\%20\%20DGNRCS.pdf $>$. Acesso em: 16 mar. 2014.

THOMÉ, Romeu. Manual de direito ambiental. 4. ed., rev., ampl. e atual. Salvador: JusPodivm, 2014.

VIEIRA, Larissa Pirchiner de Oliveira; XAVIER, Juliana Benício. A atuação do Estado frente à indústria mineradora em Conceição do Mato Dentro/MG como instrumento de (in)efetivação do texto constitucional. Em Debate. Santa Catarina: UFSC, n. 9, p. 74-89, jan/jun. 2013.

WINTER, Gerd. Proporcionalidade "eco-lógica": um princípio jurídico emergente para a natureza? Veredas do Direito. Belo Horizonte: Escola Superior Dom Helder Câmara, v. 10, n. 20, p. 55-78, jul./dez. 2013. 